\title{
Percutaneous extraction of an embolized progesterone contraceptive implant from the pulmonary artery
}

This article was published in the following Dove Press journal:

Open Access Journal of Contraception

\author{
Mohammed Majid Akhtar ${ }^{1,2}$ \\ Amit Bhan ${ }^{2}$ \\ Zhan Yun Lim² \\ Mohammed Abid Akhtar ${ }^{3}$ \\ Neha Sekhri \\ Preeti Bharadwaj ${ }^{4}$ \\ Michael Mullen² \\ 'Institute of Cardiovascular \\ Sciences, University College London, \\ London, UK; ${ }^{2}$ Department of \\ Cardiology, Barts Heart Centre, St \\ Bartholomew's Hospital, London, \\ UK; ${ }^{3}$ Department of Cardiology and \\ Cardiac Transplantation, Harefield \\ Hospital, Royal Brompton \& \\ Harefield NHS Trust, London, UK; \\ ${ }^{4}$ Community Gynaecology and Sexual \\ \& Reproductive Health Department, \\ Waltham Forest, North East London \\ Foundation Trust, London, UK
}

Correspondence: Mohammed Majid Akhtar

Cardiology Registrar, c/o Cardiac Secretaries, Barts Heart Centre, St Bartholomew's Hospital, West Smithfield, London ECIA 7BE, UK Tel +442073777000

Email majid.akhtar@ucl.ac.uk

\begin{abstract}
The Nexplanon ${ }^{\circledR}$ implant is a commonly used radiopaque contraceptive device that contains progestogen associated with an ethylene vinyl-acetate copolymer resulting in a slow release of the active hormonal ingredient. It is inserted into the subdermal connective tissue and provides contraceptive efficacy for up to 3 years. Device removal for clinical, personal or device "end-of-life span" reasons is straightforward. In rare cases, implant migration can occur locally within centimeters of the insertion site. Distant device embolization is extremely rare and can result in complications including chest pain, dyspnoea, pneumothorax and thrombosis or prevent conception until the active ingredient is depleted. We present one such case, where a Nexplanon ${ }^{\circledR}$ implant embolized into the pulmonary artery of a young female patient. We describe the initial "missed" diagnosis of embolized device on a chest radiograph and subsequent successful percutaneous removal once distant embolization was diagnosed.
\end{abstract}

Keywords: Nexplanon ${ }^{\circledR}$, pulmonary artery, embolization, extraction, snare

\section{Introduction}

The Nexplanon ${ }^{\circledR}$ implant is a commonly used radiopaque, nonbiodegradable contraceptive device that contains progestogen (etonogestrel). It is normally inserted into the subdermal connective tissue of the nondominant upper arm approximately $10 \mathrm{~cm}$ above the medial epicondyle of the humerus. During insertion, care should be taken to avoid the sulcus between the biceps and triceps as the basilic vein and its branches lie within this region.

Removal of the device for clinical, personal or device "end-of-life span" reasons is usually a simple procedure. Rarely, in $1 \%$ of cases, device removal may be complicated by hematoma, broken implant or fibrous adhesions. If an implant is unable to be palpated at the insertion site, then it should be located as soon as possible and removed. Xray or ultrasound of the arm may aid localization by identification of a radiopaque or hyperechoic line, respectively.

Rarely, implant migration can occur, but this is usually within a few centimeters of the insertion site. ${ }^{1,2}$ Distant device embolization is extremely rare and can result in complications including chest pain, pneumothorax, pleural irritation, vascular thrombosis and vascular perforation, or prevent normal conception until the active ingredient is depleted..$^{3,4}$ There have been previous rare reports of distant device embolization removed by percutaneous or surgical techniques. 


\section{Case report}

We present the case of a 31-year-old Caucasian female with a body mass index (BMI) of 22.6 that had a subdermal contraceptive implant (Nexplanon ${ }^{\circledR}$; Merck \& Co., Inc., Whitehouse Station, NJ, USA) inserted into the medial aspect of the upper arm in 2015 for contraceptive action. There were no reported complications at the time of device insertion.

She presented a year later for elective device removal as she planned on starting a family. The implant was not palpable in the upper arm and unable to be localized by ultrasound or $\mathrm{X}$-ray of the arm (Figure 1A). Etonogestrel levels were raised at $176 \mathrm{pmol} / \mathrm{mL}$ suggesting active implant in situ.

The patient also reported several weeks' history of occasional nonproductive cough. She did not suffer from any chest pain or dyspnoea. Chest X-ray (CXR) was undertaken and was reported normal by local radiologists (Figure 1B).

Given the strong clinical suspicion of embolized device, an unused Nexplanon ${ }^{\circledR}$ implant was shown to the reporting radiologists to facilitate an appreciation of the nature and physical characteristics of the foreign body being looked for. On retrospective re-review of the imaging, the radiologists subsequently identified the device implant on the anteroposterior and lateral views of the CXR. Chest CT was undertaken and revealed the presence of the contraceptive implant in a sub-branch of the right lower lobe pulmonary artery.

The patient was referred onward to the interventional cardiologists for an attempt at percutaneous extraction of the implant. Implications of leaving the device in situ include
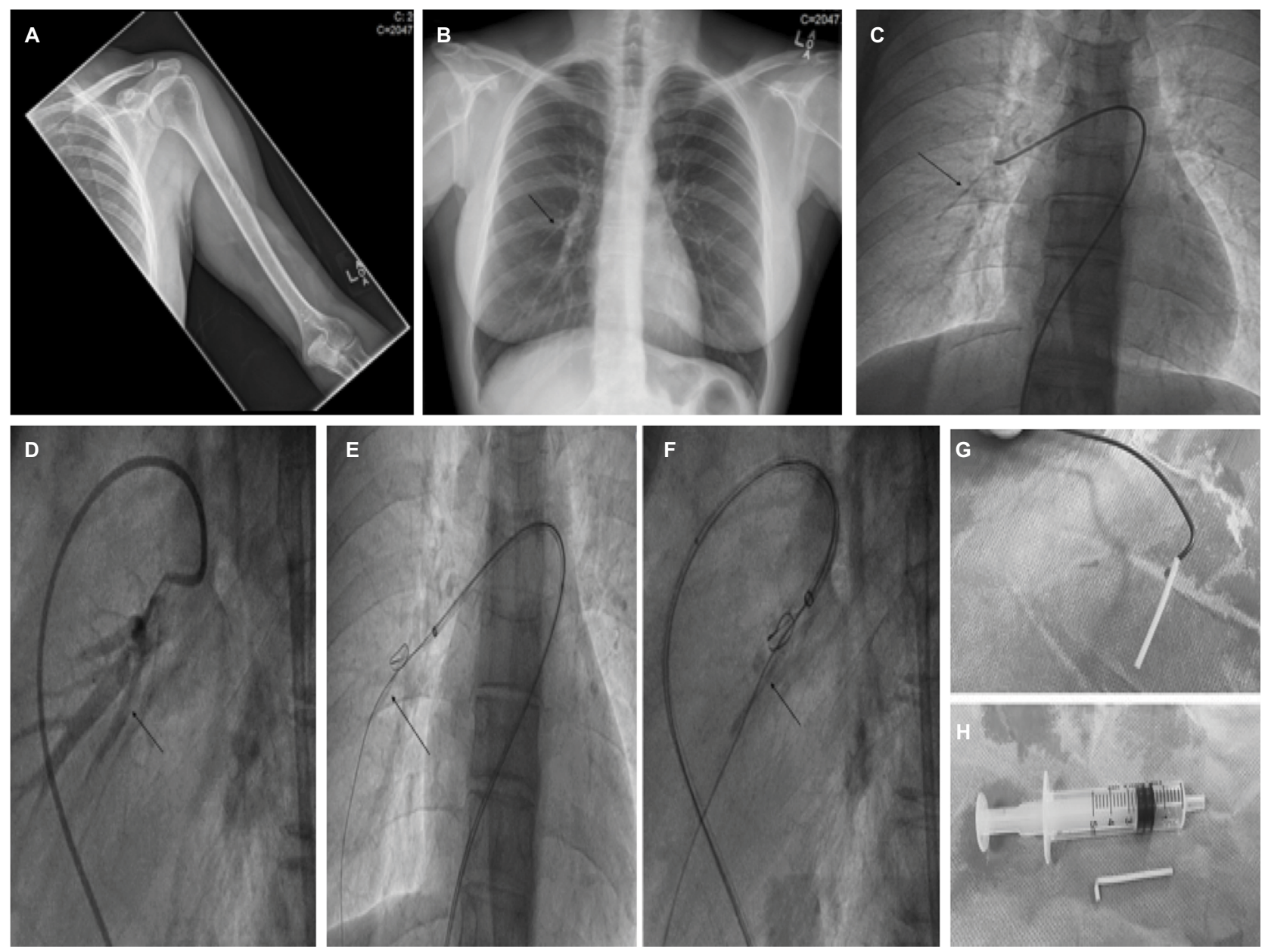

Figure I (A) AP radiograph (X-ray) of the left upper arm (humerus and cubital fossa) with no evidence of visible radiopaque subcutaneous contraceptive implant. (B) AP radiograph (X-ray) of the chest. This was initially reported as normal, but closer assessment of the right mid-zone shows the radiopaque contraceptive implant which was initially incorrectly interpreted as a prominent bronchovascular marking given its relatively short, linear outline (black arrow). On subsequent appreciation by the radiologists of the short, tubular shape of the Nexplanon ${ }^{\circledR}$ implant, the foreign body was immediately identified. (C) Judkins right (JR4) catheter positioned in the right pulmonary artery with the contraceptive implant visualized on fluoroscopy (black arrow). (D) Selective pulmonary angiography confirms the intravascular placement of the foreign body (black arrow) in a branch of the right lower lobe pulmonary artery. (E, F) AP and lateral fluoroscopy views demonstrating the utilization of a gooseneck snare to extract the foreign body from the pulmonary artery (black arrows). A straight-ended Terumo (Terumo Corporation, Tokyo, Japan) guidewire was utilized for support. (G, H) Explanted device attached to a Judkins diagnostic (JR4) catheter and the device adjacent to a $5 \mathrm{~mL}$ syringe to demonstrate size.

Abbreviation: AP, anteroposterior, 
infection, potential pulmonary arterial thrombus formation, irritant cough and reduced fertility until the active hormone ingredient is depleted.

The patient was keen on device extraction in view of a persistent cough as well as her plans for starting a family. As such, she was electively admitted as a day-case procedure for attempt at device extraction. Routine bloods and electrocardiogram were unremarkable. The procedure was undertaken in the cardiac catheter laboratory under local anesthesia from the right femoral vein using biplane angiography (Figure 1C and D). A coaxial approach was used to introduce a series of catheters into the right pulmonary artery which facilitated the capture of the device using a gooseneck snare allowing subsequent extraction of the intact device (Figure 1E-H). The procedure was uneventful and the patient discharged later in the day. She successfully became pregnant 1 month later and went on to have an uncomplicated normal delivery.

\section{Discussion}

Implantable contraceptive devices are commonly used worldwide for contraceptive efficacy and are preferred in certain patients due to improved compliance and reduced rates of user-related method failure. ${ }^{5}$ Over 3.3 million etonogestrel implants were used worldwide between 1998 and $2007 .{ }^{5}$ Over the last decade, there has been a significant increase in contraception use worldwide. ${ }^{6}$ In $2015,1 \%$ of the total worldwide contraceptive action was administered via contraceptive implants. ${ }^{7}$

Serious adverse events from device insertion such as intravascular placement are extremely rare. There are reported to be 1.3 cases of intravascular embolized Nexplanon $^{\circledR}$ implants per million units sold worldwide. ${ }^{8}$ Device embolization should be considered if the device is not palpable at the insertion site or not visualized by radiological assessment. To facilitate X-ray localization of the implant, the previous single-rod contraceptive implant (Implanon ${ }^{\circledR}$; Merck \& Co., Inc.) was modified by the addition of barium sulfate to the rod core to make it radiopaque as there were occasional reports of the Implanon ${ }^{\circledR}$ implant being unable to be located. ${ }^{9}$ This, together with the use of a new applicator for insertion, were designed to reduce the incidence of deep subcutaneous insertion. ${ }^{10}$

There are a few reported cases of contraceptive implant embolization to the axillary region, some of which required extraction via a surgical incision. ${ }^{71-13}$ There have also been a few reported previous cases of intravascular pulmonary migration of subdermal contraceptive implants..$^{2-4,74-20}$ The exact mechanism by which the implant may embolize is unclear. However, potential mechanisms include the inadvertent placement of the device into the venous system or the placement into deeper subcutaneous tissue, which may predispose to migratory forces on the implant if adjacent to a joint. It should be noted that in this reported case, device insertion preceded recommendations from the manufacturer to avoid the biceps-triceps sulcus. The manufacturer now recommends insertion $8-10 \mathrm{~cm}$ above the medial epicondyle of the humerus and to avoid the sulcus.

Patients may remain asymptomatic despite distant embolization of the contraceptive implant and diagnosis might sometimes be made during routine clinical assessment or when the device is due to be removed for various other reasons. ${ }^{7,11}$ Some patients, however, can develop untoward side effects such as chest pain or cough., ${ }^{3,9,15}$ Pulmonary migration has also been associated with pneumothorax. ${ }^{18}$

Percutaneous removal of an embolized contraceptive implant from the pulmonary artery, using a loop snare, has been described previously. ${ }^{3,17,19,20}$ In cases where the contraceptive implant has migrated too distally to allow percutaneous transluminal extraction, surgical removal may be indicated. ${ }^{2}$ In one such case, a left basal trisegmentectomy under video-associated thoracoscopy was undertaken successfully, whereas in another case at the same center, thoracoscopic removal of the device from the pulmonary artery was successful without the need for pulmonary resection or thoracotomy. ${ }^{14,16}$ There are also reported cases of the embolized device being left in situ in the pulmonary artery where it was felt that the risk from device extraction far outweighed any potential benefits or due to patient choice. ${ }^{4}$

Concerns with late diagnosis of device embolization include that unless recognized early, extraction via an endovascular approach may be difficult or hazardous due to fibrous adhesion formation with an increased risk of tearing or damaging the adjacent pulmonary vasculature. The MHRA (Medicines \& Healthcare products Regulatory Agency) has advised clinicians to undertake chest imaging if the Nexplanon $^{\circledR}$ implant cannot be located in the arm.

This particular case report demonstrates a rare case of intravascular pulmonary migration of a contraceptive implant. In this case, there was a delay in diagnosis of the embolized implant given the lack of familiarity with the physical characteristics of the device by the reporting radiologists. Where intravascular migration has been identified, interventional radiologists or interventional cardiologists may be able to assist in the removal of these devices using snares and allow a minimally invasive technique for device extraction. ${ }^{3}$ Early 
diagnosis is important to minimize the chances of adverse event from thrombus formation or localized adhesions and fibrosis, which may limit the chance of successful percutaneous extraction. ${ }^{3}$ Where percutaneous means of extraction are not feasible, there are other reported cases of minimally invasive surgical techniques for device removal.

In this case, multidisciplinary teamwork, with education of relevant health professionals, allowed subsequent rapid identification of the site of device embolization and successful removal involving minimally invasive techniques. This highlights the importance of multidisciplinary coordination and awareness of the potential complications from inadvertent deep contraceptive device insertion and potential diagnostic and therapeutic strategies to ensure a successful outcome for the patient.

Given the rarity of device embolization into the pulmonary artery, the exact mechanism by which this occurs is difficult to ascertain, particularly with regard to any retrospective recall of insertion technique or complications. The Faculty of Sexual and Reproductive Healthcare Clinical Effectiveness Unit now recommends that patients are also consented for the potential risk of device embolization prior to Nexplanon ${ }^{\circledR}$ insertion. ${ }^{21}$ Only health-care professionals fully trained and competent to insert contraceptive devices should undertake the procedure. During device insertion, the skin should be tented, and the applicator needle should be visualized along its entire length in the subdermal plane to avoid accidental deep or intravascular insertion. This, together with the recommended avoidance of the sulcus between the biceps and the triceps, a site enriched with veins and tributaries is likely to be beneficial in avoiding inadvertent placement. After device insertion, both the health-care professional and the patient should be able to palpate the device, and the patient should inform her responsible health-care clinician if she can no longer palpate the device afterward.

Pulmonary embolization is a rare complication of the Nexplanon ${ }^{\circledR}$ implant. This case highlights the importance of early diagnosis and a multidisciplinary approach to allow appropriate diagnosis and treatment of this complication. Endovascular approaches to device extraction, by interventional radiologists or interventional cardiologists, can be successful with minimal morbidity and may be considered if available locally.

\section{Consent}

The patient provided verbal and signed written consent for the development of this manuscript and its submission for publication. Care was taken to ensure no patient identifiable data was included in the manuscript. Patient written consent was obtained for case description and image usage.

\section{Disclosure}

The authors report no conflicts of interest in this work.

\section{References}

1. Ismail H, Mansour D, Singh M. Migration of Implanon. J Fam Plann Reprod Health Care. 2006;32(3):157-159.

2. Choi JH, Kim H-Y, Lee SS, Cho SH. Migration of a contraceptive subdermal device into the lung. Obstet Gynecol Sci. 2017;60(3): 314-317.

3. Chung M, Loudill C, Wieler M, Farnam J, Ahn SH. Endovascular retrieval of Nexplanon from the distal pulmonary artery. J Vasc Interv Radiol. 2017;28(3):466-467.

4. Barlow-Evans R, Jaffer K, Balogun M. Migration of a Nexplanon contraceptive implant to the pulmonary artery. BMJ Case Rep. 2017.

5. Darney P, Patel A, Rosen K, Shapiro LS, Kaunitz AM. Safety and efficacy of a single-rod etonogestrel implant (Implanon): results from 11 international clinical trials. Fertil Steril. 2009;91(5): $1646-1653$.

6. Alkema L, Kantorova V, Menozzi C, Biddlecom A. National, regional, and global rates and trends in contraceptive prevalence and unmet need for family planning between 1990 and 2015: a systematic and comprehensive analysis. Lancet. 2013;381(9878):1642-1652.

7. Kang S, Niak A, Gada N, Brinker A, Jones SC. Etonogestrel implant migration to the vasculature, chest wall, and distant body sites: cases from a pharmacovigilance database. Contraception. 2017;96(6):439-445.

8. Medicines \& Healthcare products Regulatory Agency. Nexplanon (etonogestrel) contraceptive implants: Reports of device in vasculature and lung. London: Gov.UK, Drug Safety Update; 2016. Available from: https://www.gov.uk/drug-safety-update/nexplanon-etonogestrel-contraceptive-implants-reports-of-device-in-vasculature-and-lung\#reportsand-potential-risk-factors. Accessed March 9, 2018.

9. Rowlands S, Mansour D, Walling M. Intravascular migration of contraceptive implants: two more cases. Contraception. 2017;95(2): 211-214.

10. Mansour D. Nexplanon ${ }^{\circledR}$ : What Implanon ${ }^{\circledR}$ did next. J Fam Plann Reprod Health Care. 2010;36(4):187-189.

11. Diego D, Tappy E, Carugno J. Axillary migration of Nexplanon $\mathbb{R}$ : case report. Contraception. 2017;95(2):218-220.

12. Evans R, Holman R, Lindsay E. Migration of Implanon: two case reports. J Fam Plann Reprod Health Care. 2005;31(1):71-72.

13. Uwagbai ON, Wittich AC. Migration of a subcutaneous contraceptive device. J Am Osteopath Assoc. 2016;116(9):627.

14. D'Journo XB, Vidal V, Agostini A. Intravascular pulmonary migration of a subdermal contraceptive implant. Ann Thorac Surg. 2015;99(5): 1828.

15. Patel A, Shetty D, Hollings N, Dodds N. Contraceptive implant embolism into the pulmonary artery. Ann Thorac Surg. 2014;97(4):1452.

16. Thomas PA, Di Stefano D, Couteau C, D'Journo XB. Contraceptive implant embolism into the pulmonary artery: thoracoscopic retrieval. Ann Thorac Surg. 2017;103(3):e271-e272.

17. Gallon A, Fontarensky M, Chauffour C, Boyer L, Chabrot P. Looking for a lost subdermal contraceptive implant? Think about the pulmonary artery. Contraception. 2017;95(2):215-217.

18. O'Brien A, O'Reilly MK, Sugrue G, Lawler L, Farrelly C. Subdermal contraceptive implant embolism to a pulmonary artery. Ann Thorac Surg. 2015;99(6):2254-2255. 
19. Heudes P-M, Querat VL, Darnis E, Defrance C, Douane F, Frampas E. Migration of a contraceptive subcutaneous device into the pulmonary artery. Report of a case. Case Rep Womens Health. 2015;8:6-8.

20. Pellegrino A, Damiani GR, Loverro M, Dell'Anna T, Pirovano C, Fachechi G. Distal migration of contraceptive device in a sub-segmental branch of the pulmonary artery. Eur J Obstet Gynecol Reprod Biol. 2017;215:260-261.
21. The Faculty of Sexual \& Reproductive Healthcare of the Royal College of Obstetricians \& Gynaecologists. Statement from the Clinical Effectiveness Unit: Intravascular insertion of Nexplanon June 2016. London: FSRH; 2016 Available from: https://www.fsrh.org/documents/ceu-statement-intravascular-insertion-of-nexplanon-june-2016/. Accessed March 9, 2018.

\section{Publish your work in this journal}

Open Access Journal of Contraception is an international, peerreviewed, open access, online journal, publishing original research, reports, reviews and commentaries on all areas of contraception. In addition to clinical research, demographics and health-related aspects, the journal welcomes new findings in animal and preclinical studies relating to understanding the biological mechanisms and practical development of new contraceptive agents. The manuscript management system is completely online and includes a very quick and fair peer-review system. Visit http://www.dovepress.com/testimonials.php to read real quotes from published authors.

Submit your manuscript here: https://www.dovepress.com/open-access-journal-of-contraception-journal 